\title{
DEVELANDO EL ENFOQUE TEÓRICO EN LAS INTERVENCIONES DEL PATRIMONIO EDIFICADO VIRREINAL DEL CUSCO: REFLEXIONES EN TORNO A LA RESTAURACIÓN DE LA CASA CONCHA ${ }^{(*)}$
}

\author{
UNVEILING THE THEORETICAL APPROACH WITHIN THE INTERVENTIONS OF THE VICE REGAL \\ BUILDING HERITAGE OF CUSCO: REFLECTIONS ABOUT THE RESTORATION OF THE CONCHA HOUSE
}

\author{
ALEX IVÁN USCA BACA ${ }^{(\star x)}$, BORIS HERENCIA MORMONTOY ${ }^{(* \star *)}$,

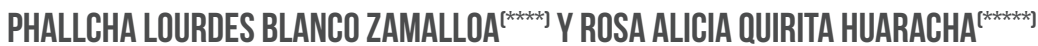

\author{
Fecha de recepción: 31 de marzo de 2017 \\ Fecha de aprobación: 29 de abril de 2017
}

\section{RESUMEN}

El presente artículo pretende analizar la aparente insuficiencia de aplicación de criterios o enfoques teóricos en los procesos restaurativos de la arquitectura virreinal del Cusco llevados a cabo durante los últimos 15 años. En tal tarea el Estado peruano, a través del hoy Ministerio de Cultura del Cusco, desempeñó un papel preponderante. En este texto se toma como caso de estudio la restauración y puesta en valor de la Casa Concha, la cual significó una excepción entre las intervenciones ejecutadas por la entidad estatal, mayormente dedicada a intervenir el patrimonio edificado de carácter religioso (templos y capillas católicos). Se ha empleado la estructura planteada por Josep María Montaner (1999) para intentar, en un primer momento, contextualizar desde el punto de vista histórico y arquitectónico los principales sucesos (hitos) que marcaron el proceso restaurativo en el ámbito cusqueño, hasta llegar a la intervención de la Casa Concha. A través de un análisis comparativo se trata de develar los enfoques teóricos y/o metodológicos utilizados en esa intervención puntual, para luego realizar el análisis formal del inmueble luego de su intervención. Finalmente, se plantea cuáles pueden haber sido los móviles y mecanismos de gestión que impulsaron el proceso hasta su ansiada apropiación social.

\section{PALABRAS CLAVE}

Contexto, restauración, adecuación

\begin{abstract}
This article tries to analyze the apparent insufficiency of theoretical criteria or approaches used in the restorative processes of Cusco's vice regal architecture carried out in the last fifteen years. In charge of such an activity, the Peruvian State, through today's Culture Ministry of Cusco, played a preponderant role. The present paper takes as case-study the restoration and revaluation of the Concha House. They were exceptional among the interventions carried out by the State, which was mostly dedicated to intervene religious building heritage (Catholic temples and chapels). In order to do this, the structure proposed by Josep María Montaner (1999) has been used. Initially, it attempts to contextualize, from the historical and architectural points of view, the main events (milestones) that marked the restorative process in the Cusco area, until we arrive to the intervention of Concha House. Through a comparative analysis, it tries to unveil the theoretical and/or methodological approaches used; to then carry out the formal analysis of the edifice after its intervention. Finally, it proposes the possible motives and management mechanisms that propelled the process to its longed-for social appropriation.
\end{abstract}

\section{KEYWORDS}

Context, restoration, adaptation

(*) Este texto se elaboró a partir de la investigación titulada Análisis de Intervención del Patrimonio Cultural Inmueble. La Casa Concha (2017), desarrollada en el Taller de Conservación del Patrimonio Arquitectónico bajo la dirección del MSc. Arq. José Hayakawa Casas, en la Maestría de Arquitectura, mención en Gestión del Patrimonio Cultural, Centros y Sitios históricos de la Universidad Nacional San Antonio Abad del Cusco (UNSAAC).

(**) Historiador de la UNSAAC. Actualmente cursa la maestría en Arquitectura, con mención en Gestión del Patrimonio Cultural, Centros y Sitios Históricos, en la misma universidad. Desde 2014 hasta la actualidad es el historiador del Programa de Investigaciones Arqueológicas e Interdisciplinarias en el Santuario Histórico de Machupicchu de la DDC-Cusco. Contacto: gonzi9887@gmail.com

(***) Arquitecto de la UNSAAC. Actualmente cursa la maestría en Arquitectura, con mención en Gestión del Patrimonio Cultural, Centros y Sitios Históricos, en la misma universidad. Es coordinador del Área de Conservación Patrimonial del Proyecto Qhapaq Nan de la DDC-Cusco. Contacto: herencia25@hotmail.com

(****) Arquitecta de la Facultad de Arquitectura y Artes Plásticas UNSAAC. Actualmente cursa la maestría en Arquitectura, con mención Gestión del Patrimonio Cultural, Centros y Sitios Históricos, en la misma universidad. Sub Directora de la Sub Dirección de Patrimonio Cultural y Defensa del Patrimonio Cultural de la DDC-Cusco. Contacto: phallcha_bz@hotmail.com (*****) Arqueóloga de la UNSAAC. Actualmente cursa la maestría en Arquitectura, con mención Gestión del Patrimonio Cultural, Centros y Sitios Históricos, en la misma universidad. Ha realizado proyectos de investigación y restauración en el Ministerio de Cultura Cusco 1994-2006. Docente de la Escuela Profesional de Arqueología de la UNSAAC. Contacto: raqui-k@hotmail.com 


\section{Contexto histórico-arquitectónico de las intervenciones restaurativas en el Cusco}

La ciudad del Cusco está ubicada en la región sur oriental del Perú, en la latitud sur $11^{\circ} 13^{\prime} 19^{\prime \prime}$, longitud oeste entre los meridianos $72^{\circ} 59^{\prime} 52^{\prime \prime}$ y $73^{\circ} 57^{\prime} 45^{\prime \prime}$, en el departamento y provincia del mismo nombre. Su fisonomía, traza, patrimonio y centro histórico son el resultado de varios periodos que se han desarrollado desde el siglo XVI hasta el presente. Durante ese largo proceso, en lo que respecta a intervenciones y restauraciones de su arquitectura monumental, está delimitada, a razón de que las instituciones como el Patronato Departamental de Arqueología del Cusco, la Corporación de Reconstrucción y Fomento del Cusco, y el entonces Instituto Nacional de Cultura tuvieron la necesidad de introducir una nueva estructura, donde sobre la base de las edificaciones prehispánicas se traslape una traza de tipo virreinal, y sobre ambos un nuevo estilo, conocido como neocolonial. Estas características arquitectónicas, que se fueron superponiendo a lo largo de varias etapas de la historia y procesos de restauración, pueden contextualizarse en tres momentos.

El primer momento que puede identificarse inicia con la creación del Patronato Departamental de Arqueología del Cusco (PDAC), conforme a las disposiciones de la Ley 6634 del 13 de junio de 1929, que en su artículo 15 refiere que "El Patronato Departamental de Arqueología del Cuzco velara por la conservación, protección, investigación y estudio de todos los monumentos arqueológicos comprendidos en la presente Ley situados en el Departamento del Cusco..." (Ministerio de Educación Pública, 1929, p. 7). En efecto, las disposiciones legislativas consideradas en la Ley 6634 eran de carácter netamente arqueológico: la prioridad del Estado era la conservación y restauración de tales monumentos. Así, en 1934, con motivo de las celebraciones del cuarto centenario de la fundación española del Cusco, el Estado peruano otorgó un presupuesto para realizar trabajos de investigación, conservación y restauración de los monumentos de la ciudad. En el artículo $22^{\circ}$, sobre la obligación gubernativa, figura que "El Gobierno proveerá lo necesario para la conservación y reparación de las ruinas y yacimientos arqueológicos que se declaren monumentos nacionales por leyes especiales, y en todo caso de los yacimientos arqueológicos de Saqsayhuaman, Ollantaytambo, Machu Picchu" (Ministerio de Educación Pública, 1929, p. 8). En estas circunstancias el Estado peruano, a través de estas normas legislativas, iniciaba un proceso de custodia del patrimonio cultural arqueológico (mueble e inmueble) y la recuperación de importantes sitios arqueológicos. Respecto de estas intervenciones iniciales Roberto Samanez afirma que "en estas intervenciones de los años 1933-1934 se incurrió en prácticas inadecuadas, muy alejadas de la orientación que daría posteriormente la UNESCO en las recomendaciones que definen los principios internacionales para aplicarse en materia de excavaciones arqueológicas de 1956" (2016, p. 114).

El segundo momento se inicia con el terremoto de 1950, fenómeno que marcaría un punto de quiebre en la producción arquitectónica, y el surgimiento e incorporación de un nuevo estilo neocolonial. En efecto, en la ciudad del Cusco, antes del terremoto, predominaban la arquitectura virreinal y republicana, y se mantenía un tejido urbano compuesto por calles estrechas, y casas de piedra y adobe sin alteraciones. Fue esa fisonomía la que lamentablemente sufrió severos daños a consecuencia del terremoto acaecido el 21 de mayo: se derrumbaron cientos de casonas y templos con el impacto inicial, mientras que otros quedaron tan dañados que debieron ser demolidos en los días subsecuentes. Los diarios locales EI Sol y El Comercio, reaparecidos a los pocos días del terremoto, anunciaron con certera intuición algunos titulares como "El Plan Piloto y la Reconstrucción del Cusco", "La Reconstrucción del Cusco" y “Cómo Ha Quedado el Cusco Después del Terremoto" (Figura 1).

Tras el terremoto, los ingenieros del Ministerio de Fomento empezaron a rivalizar entre ellos en las obras de demolición. Cuerpos de ingenieros recorrían el Cusco, sentencian- 


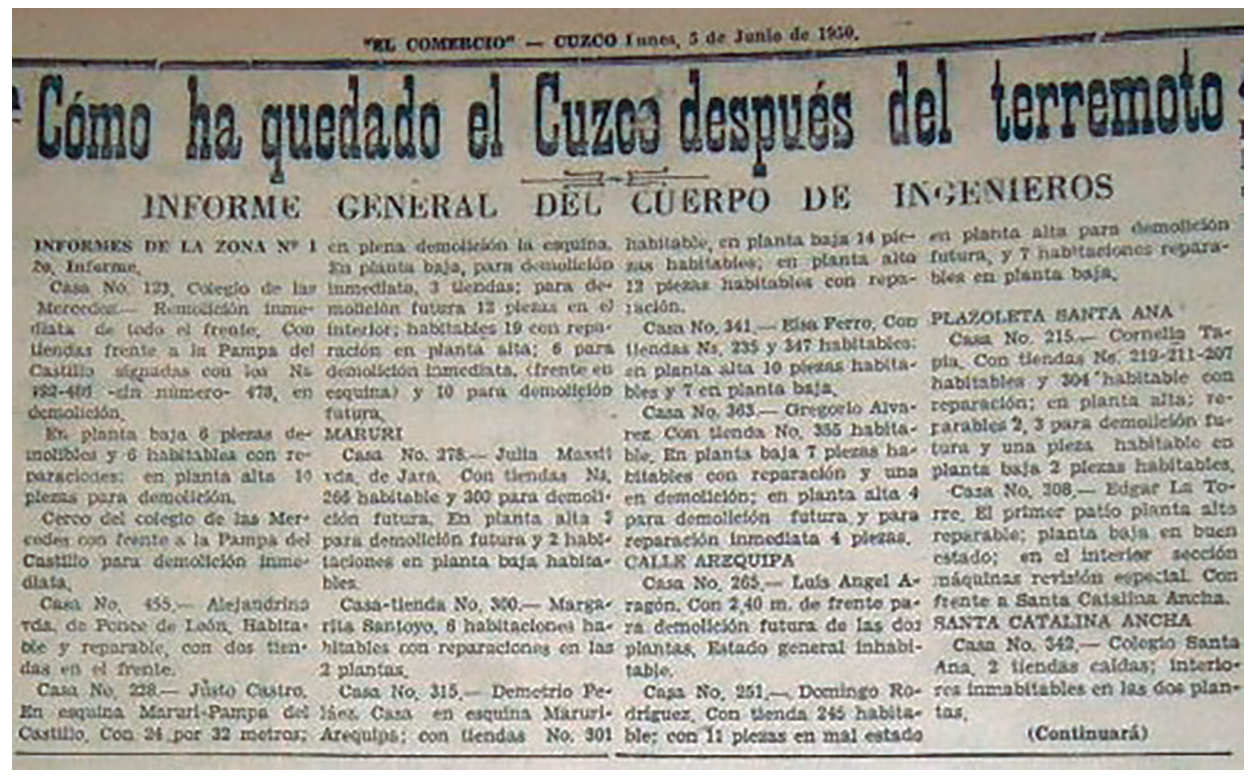

do sin posibilidad de apelación qué casonas y viejas residencias debían ser demolidas para siempre. La reconstrucción de la ciudad imperial planteada por este equipo de ingenieros, técnicos, arquitectos y urbanistas se hizo en circunstancias nada convenientes; atentó contra toda clase de intereses particulares y públicos, y no respetó el carácter arqueológico, la integridad y el majestuoso aspecto de la ciudad.

En 1951, como parte de la comisión del Plan Piloto, el ingeniero Luis Miró-Quesada Garland propuso sobre la "Reconstrucción del Cusco" un cuádruple tratamiento: "La zona histórica de valor arqueológico notable, las zonas urbanas susceptibles de modificación, la zona urbana remoldeable totalmente y las zonas futuras íntegramente proyectables" (El Sol del Cusco, 1951, 14 de noviembre, p. 6). En esta propuesta inicial del Plan Piloto, en cuanto a la categoría zona urbana remoldeable totalmente, el ingeniero hace propuestas más radicales y enfáticas respecto a remudar o renovar las edificaciones de la antigua ciudad, inaparente para recibir las nuevas edificaciones, y afirma que debe crearse un emplazamiento libre, lógico y adecuado, "una zona específica que constituya el núcleo vivo y principal de la ciudad" (Miró-Quesada y sus contemporáneos parecían odiar la ciudad antigua, porque derribaron en ciega competencia muchas casonas del Cusco colonial sin pensar siquiera en la posibilidad de restaurarlas. El informe de Kluber (1953) los acusa sin remedio: "Los trabajos de descombro, iniciados muy poco después del terremoto por equipos de peones camineros, fueron culpados de haber producido un $20 \%$ de las demoliciones" (p. 5). El impacto psicológico provocado por el terremoto trajo consigo el rechazo a cualquier posibilidad de conservar lo antiguo; se alentaron las demoliciones y el ensanchamiento de las calles. Este proceso también comprometió a la arquitectura religiosa (templos y conventos), cuya destrucción se hubiese consumado de no ser por la intervención enérgica de Luis E. Valcárcel, quien a través de su opinión consiguió defender los monumentos y evitar su precipitada demolición. En sus Memorias, al respecto, Valcárcel (1976) afirma que su discurso era el siguiente: "No queremos más cosas antiguas, queremos un Cuzco nuevo, hay que desaparecer el Cuzco antiguo, basta de Cuzco viejo" (p. 167).

A consecuencia de la catástrofe del 21 de mayo de 1950, los políticos cusqueños se empeñaron en conseguir un instrumento legal que financiara y organizara la tarea de reconstrucción, que concebían como más que una tarea de restauración. No obstante, el ansia de los cusqueños por reedificar su ciudad no esperó planes ni iniciativas es-
Figura 1. Como ha quedado el Cusco después del Terremoto. Informe general del cuerpo de ingenieros [Artículo periodístico]

Fuente: El Comercio del Cusco (p. 2), 5 de junio de 1950. 


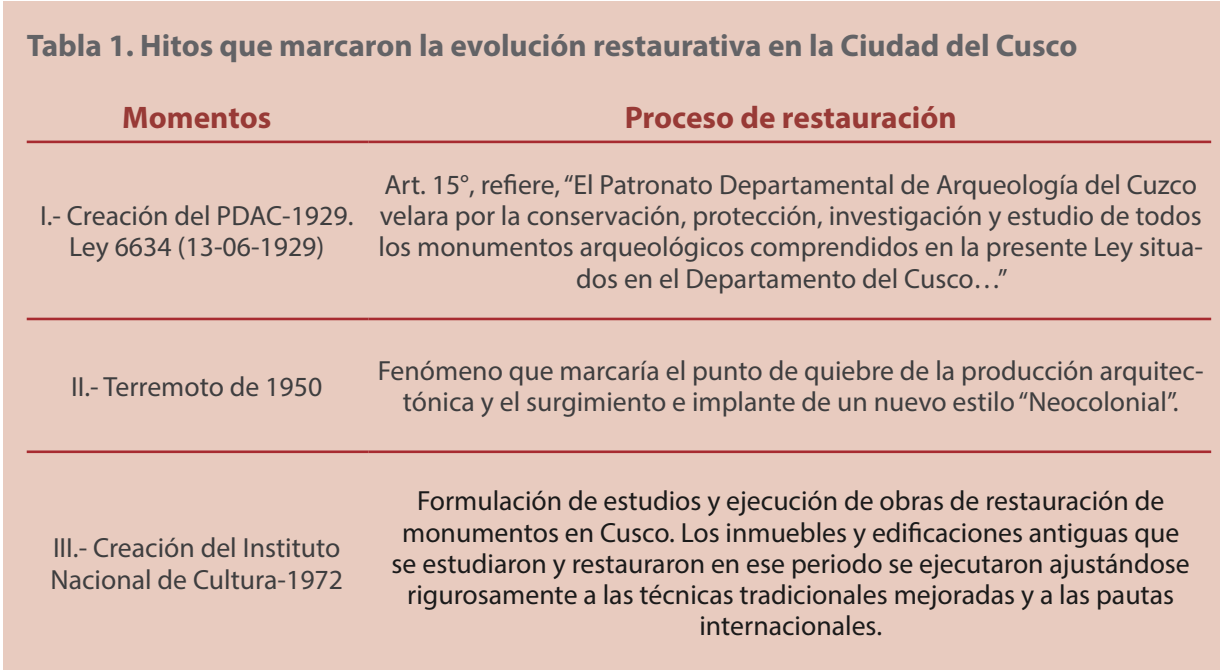

Fuente: Elaboración propia, 2016.

tatales: el proceso autónomo de reconstrucción se inició desde las primeras semanas siguientes al terremoto. Los habitantes del Cusco, con sus escasos recursos, empezaron a apuntalar sus viviendas y casonas, tratando de salvarlas. Fue una tarea silenciosa, multitudinaria y anónima, que demostró que los cusqueños se negaban a dejarse vencer por el infortunio. Entonces, iniciada la reconstrucción y restauración de los monumentos incas y coloniales, emergió la sabiduría de la mano de sus ancestros; aparecieron canteros, talladores y alarifes que resucitaron las técnicas aparentemente perdidas. Resucitó del pueblo la mano maestra, que sin escuela ni técnica ortodoxa o importada labró la piedra para hacerla columna, arco o estatua. Ellos fueron los héroes ignorados de una gran tarea colectiva, pues sin la mano sabia y la paciencia indígena de quienes podían pasarse días y semanas labrando una piedra o un retablo la tarea hubiera sido imposible. Nadie sabía técnicas ni procedimientos, la Carta de Venecia no existía, y la tarea era urgente e ineludible por la proximidad de las lluvias y el temor ante la posibilidad de un nuevo sismo. Pero la tarea no consistía solo en restaurar con exactitud, sino sobre todo con seguridad; había que prever un futuro sismo. Así, se dotó a los monumentos coloniales de estructuras de concreto para absorber las aceleraciones, sin sacrificar su apariencia externa. Esencial era salvar su estilo y mejorar su asismicidad, tareas que se cumplieron cabalmente por obra exclusiva de profesionales locales.

Un tercer momento en la historia de las restauraciones en Cuzco inicia con la creación del Instituto Nacional de Cultura (INC) en 1972, organismo desde el cual se formularon estudios y se ejecutaron obras de restauración de monumentos en la ciudad. Los inmuebles y edificaciones antiguos que se estudiaron y restauraron durante este tercer periodo se ejecutaron ajustándose rigurosamente a las técnicas tradicionales mejoradas y a las pautas internacionales, como la Carta de Venecia (1964), cuyo artículo $9^{\circ}$ señala que "La restauración es una operación que debe tener un carácter excepcional. Tiene como fin conservar y revelar los valores estéticos e históricos del monumento y se fundamenta en el respeto a la esencia antigua y a los documentos auténticos" (INC, 2007, p. 138). Esa norma internacional fue el referente cotidiano para que todos los arqueólogos, arquitectos y restauradores no solo ejecuten su trabajo, sino transmitan y capaciten al personal obrero que en el pasado había realizado prácticas alejadas de las teorías que sustentan la restauración. En este contexto, a finales del siglo XX y principios del siglo XXI, la rehabilitación del patrimonio arquitectónico es uno de los ejes fundamentales que está condicionando y que condicionará durante los próximos 
decenios el desarrollo de las ciudades. En muchos casos los recursos públicos se han invertido preferentemente en los edificios de mayor prestigio: catedrales, plazas, palacios, monasterios e iglesias; al mismo tiempo, el desarrollo del turismo ha canalizado los recursos privados hacia la construcción de hoteles, restaurantes y empresas de servicios que han ocupado el entorno urbano de los monumentos restaurados. Esta dinámica ha favorecido la conversión de los centros monumentales en "museos al aire libre".

A lo largo de este proceso de cambio la arquitectura cusqueña (inca, virreinal y republicana), ha mantenido sus características, como la solidez, el color, el espacio, etc. No obstante, en un mayor porcentaje predomina el patrón virreinal, sobre todo en lo que respecta al esquema espacio funcional constructivo. Durante el periodo republicano se introdujeron nuevos recursos decorativos: frontones, frisos cornisas y molduras. Asimismo, en la actualidad, si bien aún se usa adobe como material constructivo básico, se ha introducido el uso de la madera (el trabajo de la carpintería es maquinado y se cambia de escuadría en las vigas), e iniciado la importación de piezas prefabricadas de fierro para balcones, galerías y ventanas.

El monumento arquitectónico de la Casa Concha, declarado Patrimonio Cultural de la Nación el 13 de diciembre de 1972, se encuentra ubicado en la calle Santa Catalina Ancha. Está signado con el №320 y es parte integrante de la manzana $\mathrm{N}^{\circ} 19$ del Centro Histórico. Se caracteriza porque muchas de sus estructuras están construidas sobre la base de muros incas, al igual que numerosas casas españolas de adobe que fueron refaccionadas desde la Colonia hasta principios del siglo XXI. Mediante la Resolución Suprema N ${ }^{\circ}$ 2900-72-ED del 13 de diciembre de 1972, la Casa Concha fue declarada patrimonio arquitectónico, razón por la cual se gestionó ante las autoridades competentes la conservación y restauración de tan importante patrimonio cultural inmueble. Así, instituciones como COPESCO, el INC y la Universidad San Antonio Abad del Cusco pusieron en marcha su restauración y puesta en valor, con el propósito de destinarla al funcionamiento de un complejo cultural de investigación arqueológica como parte del circuito turístico y cultural de la ciudad del Cusco (Tabla 1).

\section{Redescubriendo a los especialistas}

Al parecer, la práctica restaurativa de los últimos años en la región Cusco se ha desarrollado en dos frentes: el primero, a cargo del Estado peruano, que a través de la hoy Dirección Desconcentrada de Cultura del Cusco (DDC-C) se ha "especializado" en intervenir el patrimonio edificado de carácter religioso (templos); el segundo, a cargo de inversiones privadas (generalmente entidades financieras) que han optado por la restauración de la arquitectura civil (casas). Es precisamente desde este segundo frente que se han ejecutado las intervenciones más significativas. Un claro ejemplo de ello es la restauración de la Casa Cabrera, un destacado modelo de aplicación de criterios y tecnologías restaurativas.

En este contexto, la restauración y puesta en valor de la Casa Concha parece haber sido una excepción a la regla, ya que tanto la elaboración del expediente técnico como su ejecución física estuvieron íntegramente a cargo de la DDC-C. Sin embargo, a diferencia de otras intervenciones en arquitectura civil, la restauración de la Casa Concha no ha recibido mayores elogios; por el contrario, ha pasado prácticamente desapercibida.

Existe un consenso más o menos generalizado sobre que la mayoría de las restauraciones en edificaciones religiosas Ilevadas a cabo por la DDC-C tienen una constante: en las investigaciones preliminares puede percibirse una marcada inclinación a ponderar el análisis formal y estilístico por encima de las investigaciones de carácter histórico, tecnológico o constructivo, por citar solo algunas. Esta deficiencia en el conocimiento integral -sobre todo científico- de la singularidad del objeto de intervención ha derivado muchas veces en la estandarización de los planteamientos restaurativos, que a su vez han devenido en la casi nula necesidad de incorporar un adecuado y sistemático 
Tabla 2. Procedimiento de Intervención

\begin{tabular}{ccc} 
Objetivos & Restauración & Puesta en valor \\
\hline $\begin{array}{c}\text { Procedimiento de } \\
\text { intervención }\end{array}$ & Restauración & Adecuación \\
\hline Premisas & $\begin{array}{c}\text { - Integral } \\
\text { - Aplicar tecnología apropiada } \\
\text { - Recuperar la concepción origi- } \\
\text { nal, conservando sus elementos, } \\
\text { eliminando adiciones sin valor } \\
\text { y restituyendo elementos indis- } \\
\text { pensables }\end{array}$ & $\begin{array}{c}\text { - Refuncionalización compatible } \\
\text { - Evitar desvirtuar cualidades patrimo- } \\
\text { niales }\end{array}$ \\
- Garantizar su conservación a través \\
& $\begin{array}{c}\text { de actividades y/o nuevos usos, que le } \\
\text { darán vida propia }\end{array}$
\end{tabular}

Fuente: Elaboración propia a partir del Expediente Técnico de Restauración y Puesta en Valor de la Casa Concha- 2007 (p. 82-86), por J. Cano Pozo, 2007, Cusco, Perú: Instituto Nacional de Cultura del Cusco.

marco teórico-conceptual para afrontar las restauraciones. Tal proceder va en contra de los postulados de la Carta de Venecia (1964), documento que requiere que se descubran los valores artísticos e históricos de cada edificio.

Es factible entonces que dicha deficiencia se haya repetido al afrontar la intervención de la Casa Concha. Una probable constatación de ello es la insuficiencia de criterios teóricos y técnicos expuestos en su expediente técnico, cuya consideración hubiera permitido ampliar aspectos conceptuales y de orientación del proyecto de restauración. No obstante -a la luz de los hechos-ciertamente se pudo recuperar la edificación de su paulatina pero inexorable pérdida total. Se logró finalmente su puesta en valor a través de una adecuación y asignación de nuevos usos públicos.

Cabe analizar en este caso en particular las dos pautas o premisas que guiaron la intervención en la Casa Concha:

1. “La intervención restaurativa de la Casa Concha deberá ser integral, considerando el edificio y sus características artísticas, como elementos arquitectónicos y la pintura mural, debiendo aplicar la tecnología apropiada para recuperar el monumento en su concepción original, conservando respetuosamente todos y cada uno de sus elementos, eliminando las adiciones que no constituyan aporte $y$, restituyendo aquellos indispensables de los que se hayan encontrado suficientes evidencias de su existencia." ${ }^{11}$

2. Se propone una adecuación a nuevo uso mediante: "Una refuncionalización compatible con el monumento, que no lo desvirtúe y sobre todo que garantice su conservación dentro de una dinámica de actividades que le darán vida propia a este importante inmueble"2.

Ambas declaraciones contienen implícitamente un derrotero a seguir, una "hoja de ruta" para la intervención; así, se enmarcaron dos grandes objetivos: la restauración y la puesta en valor, y se identificó para cada uno dos procedimientos de intervención: la restauración integral y la adecuación para uso nuevo, definiendo a su vez pautas y/o premisas a cumplir en cada caso (Tabla 2).

\footnotetext{
1. Énfasis del autor.

2. Énfasis del autor.
} 
Al margen de ello, cabe preguntarse si esta conceptualización interventiva fue suficiente para desarrollar todo el proceso de restauración y puesta en valor. La respuesta es que definitivamente no: ello -a nuestro entender- fue complementado por la experiencia, capacidad y habilidad de todo un equipo multidisciplinario de especialistas conformado por arquitectos, arqueólogos, ingenieros y restauradores, quienes al mando de personal obrero eficiente y altamente calificado volcaron todo el conocimiento adquirido sobre tecnologías constructivas tradicionales en el proceso de restauración y puesta en valor.

Sin embargo, como ha sido la constante en nuestro ámbito, ya sea por la falta de confianza en el adobe o por el peligro latente de los sismos, el criterio restaurativo que prevaleció fue el estructural. Sobre el particular, el Arq. Roberto Samanez (1991) afirma lo siguiente: "La finalidad de la restauración es la de proteger y prolongar la vida de los monumentos, consolidándolos desde el punto de vista estructural, pero sin alterar su esencia ni su forma" (1991, p. 297). En esa misma línea, fue posible identificar interesantes coincidencias con la intervención ejecutada en la Casa Cabrera, en lo que se refiere a criterios de orden estructural, las cuales pueden observarse en la Tabla 3.

Si se tiene en cuenta que para el proceso llevado a cabo en la Casa Cabrera se conceptualizó un marco teórico de intervención que tuvo como eje rector a la Carta de Venecia, entonces se podría inferir -sobre la base de las coincidencias halladas- que también el proceso ejecutado en la Casa Concha tenía un sesgo "veneciano"; sin embargo, durante la fase operativa de ejecución física, ambas intervenciones tomaron vertientes totalmente disímiles: una contemporánea, invasiva, fachadista, y otra -la de la Casa Concha- tradicionalista, artesanal, auténtica. En una se usaron portentosos pórticos de concreto armado, y en la otra humildes pero efectivos tensores de rollizo eucalipto.

En este punto no se pretende calificar cuál procedimiento fue mejor, pero sí es posible afirmar, cuál fue el más respetuoso en tanto tecnologías constructivas tradicionales y materiales autóctonos, y, por tanto, auténtico: "Son preferibles las técnicas y materiales tradicionales para la conservación de la fábrica significativa" (Carta de Burra, 1999, p. 2).

Tabla 3. Coincidencias de intervención de orden estructural

\begin{tabular}{|c|c|c|}
\hline Criterio & Casa Concha & Casa Cabrera \\
\hline \multirow{4}{*}{$\begin{array}{l}\text { Procedimientos de } \\
\text { intervención }\end{array}$} & Devolver las condiciones de estabilidad al monumento & Asegurar la estabilidad del edificio \\
\hline & $\begin{array}{l}\text { Consolidar las diferentes estructuras portantes desde la } \\
\text { cimentación, sobre cimentación y los muros de adobe, así } \\
\text { como las estructuras de techos }\end{array}$ & $\begin{array}{l}\text { Llevar a cabo una restauración de consolidación que ga- } \\
\text { rantice el adecuado comportamiento estructural de muros, } \\
\text { pisos y techos, respetando las partes originales y el sistema } \\
\text { constructivo empleado }\end{array}$ \\
\hline & $\begin{array}{l}\text { Restituir tipológicamente las cubiertas con estructuras de } \\
\text { "par y nudillo" }\end{array}$ & $\begin{array}{l}\text { Restituir los techos originales con el sistema de armaduras } \\
\text { de "par y nudillo" }\end{array}$ \\
\hline & $\begin{array}{l}\text { Implementar refuerzos estructurales que garanticen la } \\
\text { estabilidad estructural del edificio }\end{array}$ & $\begin{array}{l}\text { Restituir la capacidad resistente del conjunto mediante la } \\
\text { introducción de refuerzos estructurales }\end{array}$ \\
\hline Estético & Cerrar tres vanos de puerta, en la fachada principal & $\begin{array}{l}\text { Eliminar y cerrar seis grandes ventanas abiertas indiscrimi- } \\
\text { nadamente en la fachada principal }\end{array}$ \\
\hline
\end{tabular}

Fuente: Elaboración propia a partir de Expediente Técnico de Restauración y Puesta en Valor de la Casa Concha - 2007 (pp. 82-86), por J. Cano Pozo, 2007, Cusco, Perú: Instituto Nacional de Cultura del Cusco, y"La Casa de don Jerónimo Luis de Cabrera y de la Cerda en el Cusco, su Historia y Restauración Arquitectónica", por R. Samanez Argumedo, 1991. Revista del Museo e Instituto de Arqueología, 296-311. 


\section{Análisis formal}

Para entender la restauración y puesta en valor de la Casa Concha, se debe analizar primero qué es y qué importancia tiene la casa virreinal, específicamente en la ciudad en cuestión. A diferencia de las casas virreinales de otros centros urbanos, en las características de las casas edificadas por los españoles en Cusco influyeron ciertos condicionamientos determinados por la disposición topográfica de las kanchas incaicas, sobre las que fueron superpuestas las casas virreinales: estas tuvieron que acomodarse a la traza básica del perímetro establecido por los muros bajos que se aprovecharon, y en algunos casos también por la distribución de algunas habitaciones del primer piso (San Cristóbal, 2001, p. 1).

En un trabajo sobre los patrones de asentamiento en la ciudad del Cusco, el arquitecto Carlos Castillo Venero diferencia un primer período colonial en la evolución urbana del Cusco, que denomina "de transición" (1970, p. 105).

En lo que se refiere a las viviendas típicas de este período colonial, en las kanchas incas se usan primero los recintos existentes en su forma primitiva, y luego se modifican espacial y formalmente, además de la implementación de nuevas técnicas, adobes y tejas, con lo que se constituye la típica casa cusqueña de la época: "La Casa cusqueña se desarrolla en la típica planta de raigambre hispánica en torno a uno o dos patios, uno principal y los demás secundarios o de servicio" (San Cristóbal, 2001, p. 3).

La disposición morfológica de la casa cusqueña virreinal correspondía a tal modelo típico de casa cusqueña en el primer patio, independientemente del número de patios con que contaba cada casa y de que además el segundo patio solo reunía habitaciones para ciertos servicios adicionales de acuerdo al rango económico del propietario, no para el uso familiar y social directo. La planta de la casa virreinal cusqueña era básicamente monoespacial: estaba organizada en torno a un patio central. La apertura de un segundo patio en ciertas casas no modificaba la composición monoespacial del sector familiar y social de la vivienda. La casa cusqueña era una unidad morfológica concentrada hacia el interior, en torno al primer patio como núcleo organizador de la distribución de las habitaciones familiares y sociales (San Cristóbal, 2001).

En las casas cusqueñas que cuentan con dos pisos superpuestos, se observa el contraste notorio entre el número de habitaciones más cortas de las cuatro crujías laterales que delimitan el primer piso en el patio principal y el menor número de habitaciones más largas existentes en el segundo piso del mismo patio. A diferencia de las casas virreinales limeñas, en las de Cusco no coincide la colocación de los muros transversales divisorios de las habitaciones en las crujías de los dos pisos superpuestos. La menor longitud de las habitaciones del primer piso puede corresponder a las habitaciones pequeñas de las kanchas incaicas, o haber estado condicionada por aquella topografía de las habitaciones prehispánicas, mientras que las habitaciones más espaciosas del segundo piso tenían la disposición preferida por los vecinos españoles. También es posible que en algunas casas se haya subdividido alguna habitación del primer piso para formar tiendas de alquiler. El empleo simultáneo de corredores con arquerías de piedra es una de las características específicas de los patios en las casas virreinales cusqueñas, tipología peculiar de la escuela arquitectónica regional del Cusco (San Cristóbal, 2001).

\section{Tipificación de inmuebles}

\section{Casa solariega}

Es el nombre genérico que se da a las casas construidas según los cánones hispanos durante la Conquista, debido a que en la repartición de tierras a la parcela que le tocó a cada conquistador se le denominó solar. Estas casas tienen en planta la disposición 
Tabla 4. Características de las casas virreinales en el Cusco

Características

Fueron acondicionadas a las disposición de las kanchas incas.

La casa cusqueña se desarrolla en torno a uno, dos o más patios.

La planta de la casa virreinal cusqueña era básicamente monoespacial.

Presentan corredores arqueados en los patios de vivienda.

Fuente: Elaboración propia, 2017.

de la llamada casa andaluza o extremeña: edificaciones casi siempre de dos niveles, articuladas alrededor de un patio central y, según la importancia del inmueble en particular, con uno, dos o tres patios interiores con igual disposición.

Según la importancia de estas casas y la época de su construcción, pueden contar con arquerías en una, dos y tres alas del primer patio, y en el primer y segundo nivel. En otros casos, el segundo nivel está circundado por corredores que sirven de circulación a las habitaciones existentes. Los segundos y terceros patios cuentan con edificaciones de uno y dos niveles, con corredores alrededor del patio. Otras poseen un canchón o huerta interior. La caja de escaleras del primer patio es generalmente tratada con pasos de sillería de piedra, cuyo arranque y descanso inician y culminan en arco de medio punto en adobe o piedra. Tienen invariablemente un zaguán de ingreso, al cual se accede a través de una portada cuya forma varía de acuerdo a la época (Gutiérrez, De Azevedo, \& Viñuales, 1981).

\section{Casa colonial o transicional}

Estos inmuebles fueron edificados empleando tecnología y mano de obra nativa, por lo que las portadas de acceso se asemejan a las incas, de tipo trapezoidal y con el muro inclinado (talud). En el Cusco quedan muestras importantes de estos inmuebles, aunque en general, como consecuencia de las sucesivas ocupaciones de estos inmuebles, en la actualidad muestran una tipología correspondiente a otra época de ocupación (Tabla 4).

\section{Casa Concha ${ }^{3}$}

La Casa Concha, el más destacado ejemplo de la arquitectura civil cusqueña del siglo XVIII, consiste en edificaciones de dos niveles alrededor de cuatro patios de características variadas, y un canchón encerrado por las edificaciones vecinas. Ocupa íntegramente el lote, que al parecer no ha sufrido desmembraciones y corresponde al solar original.

La amplia fachada, hacia la calle Santa Catalina Ancha, muestra la acertada superposición de la arquitectura mestiza sobre las bases de las estructuras de la arquitectura prehispánica. En el primer nivel, se conservan casi íntegros los muros de mampostería concertada de la original kancha inca, que fueron cortados para ampliar o aperturar vanos, y reacondicionarlos a las formas y usos de la nueva arquitectura. La casa muestra en su trazo actual cuatro patios, lo cual diferencia la zona social de la de servicio, como era frecuente.

3. Resumen elaborado sobre la base del Informe Anual de Reliquidación de la Restauración y Puesta en Valor de la Casa Concha - 2010, por J. Cano Pozo, 2010, Cusco, Perú: Instituto Nacional de Cultura. 


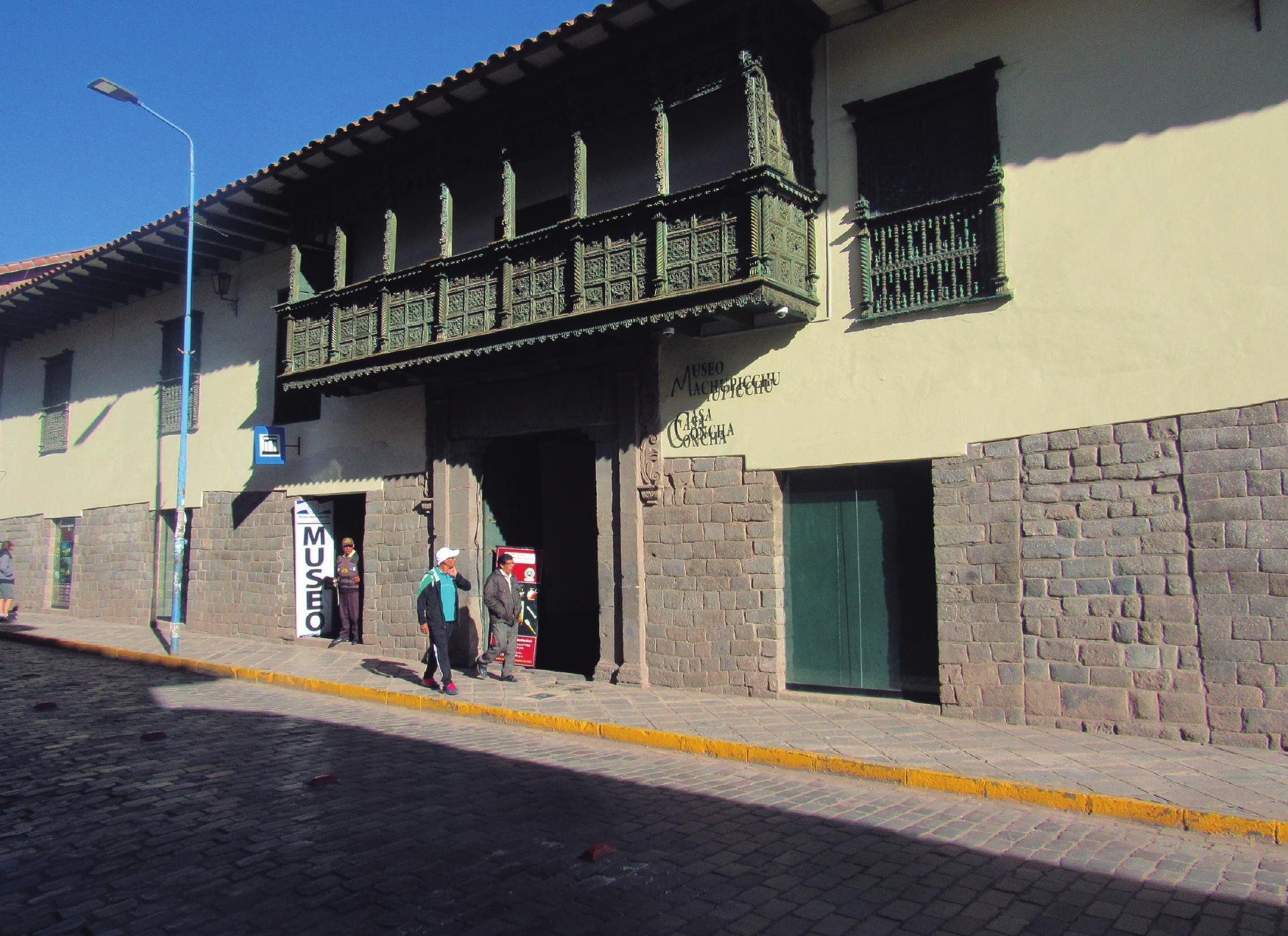

Figura 2. Vista de la fachada de la Casa Concha

Fuente: Fotografía por Alex Usca, 2017
El ingreso principal está ubicado en la actual calle Santa Catalina, y desemboca, a través de un zaguán de ingreso, en un patio principal que se encuentra rodeado por arquerías de piedra en sus tres costados y en los dos niveles. La cuarta ala posee una galería de madera en el segundo nivel. El patio que en la actualidad sirve de vestíbulo de distribución para los diferentes ambientes que se encuentran en torno a este (Figuras 2, 3, 4 y 5).

En el ala Sur se ubican dos arcos de acceso al segundo y tercer patio, y una puerta a lo que fue la capilla de la casa (de planta rectangular, muy alargada, con una cúpula simple a la altura del presbiterio). En el ala Oeste se encuentra la caja de escaleras en piedra labrada de dos tramos, en forma de U, la cual está resguardada por una puerta tipo cancela de madera. Además, se encuentran tres ambientes en regular estado de conservación.

El ingreso principal está remarcado por una sobria portada, constituida por jambas de piedra cuyos remates se prolongan en modillones decorados con roleos, que portan un dintel monolítico decorado también con labra de escusones, roleos y motivos diversos en bajo relieve. Existen tres vanos de puerta a cada lado de la portada. En el lado derecho (Noreste), los vanos son similares y equidistantes. En el lado izquierdo (Suroeste), dos de los vanos son simétricos y equidistantes, y el tercero, que corresponde al lado extremo, es más amplio, por lo que forma una portada secundaria. En el segundo nivel el número de vanos se repite, y corresponde con ligeras diferencias a la ubicación de las puertas de la planta baja. El vano central, ubicado sobre la portada principal, es el acceso al balcón volado que se constituye en el elemento decorativo más importante del conjunto. 


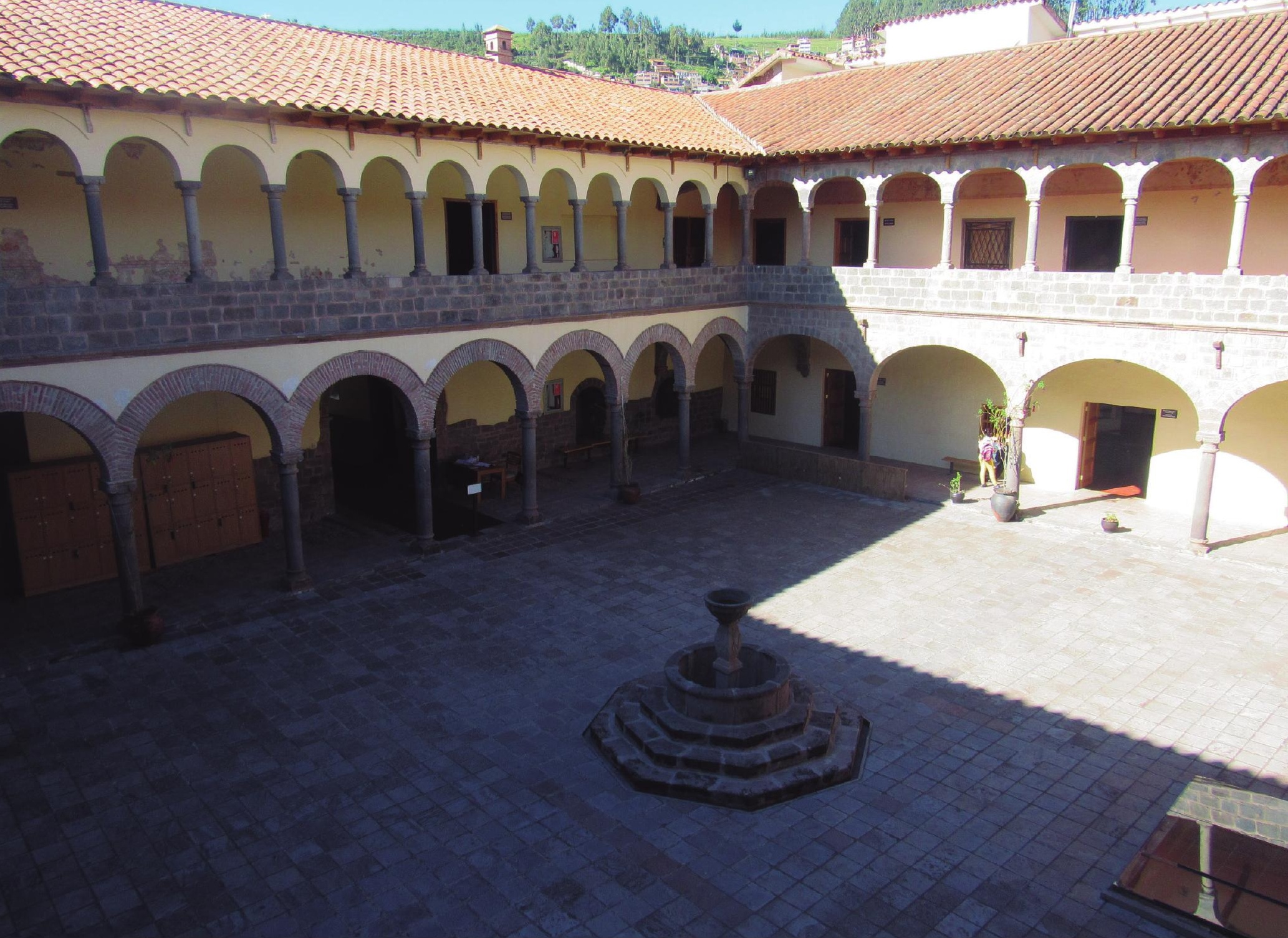

El primer patio, cuya figura es ligeramente trapezoidal, está delimitado por construcciones de adobe en dos niveles. La crujía de fachada y las dos laterales tienen amplias galerías de arcadas de piedra en ambos niveles; en cambio, la crujía del fondo cuenta solamente con una galería de madera en la segunda planta, la cual da origen a un corredor que comunica las galerías laterales y sirve de acceso a los ambientes de este sector.

En el primer nivel, la galería de la crujía de fachada o Noroeste está conformada por una arcada de arcos de medio punto; la galería del lado Suroeste está conformada por una arcada de cinco arcos carpaneles, de mayor luz que los de medio punto; y la galería del lado Noreste está conformada por una arcada de cinco arcos carpaneles, de mayor luz que los de las galerías previamente descritas. En todos los casos, las columnas son de sección circular con bases y capiteles de planta cuadrada. Por la amplitud en el trazo de las galerías, los arcos de apoyo en los muros perimetrales son también carpaneles.

En el segundo nivel, las arcadas están asentadas sobre un antepecho que a su vez descansa en el cornisamento de las galerías del primer nivel. En la galería de la crujía de fachada se cuentan 15 arcos de medio punto, por lo que su distribución es irregular con relación a las arcadas de la planta baja. En las galerías laterales se encuentran 10 arcos carpaneles, de los cuales dos corresponden a cada arco de la planta baja. En este nivel las galerías resaltantes son amplias, los arcos de apoyo en los muros perimetrales son tendidos, los vanos resultantes en las arcadas de las tres galerías de piedra de la planta alta han sido cerrados con ventanales de madera que contornan su figura y en los accesos que dan paso al corredor se han acondicionado puertas del mismo material.
Figura 3. Vista actual del primer patio

Fuente: Fotografía por Alex Usca, 2017 
devenir Vol. 4, N7, ENERO- JUNIO 2017, PP. 49-68 - ESTUDIOS | ISSN 2312-7562

UNIVERSIDAD NACIONAL DE INGENIERÍA, LIMA

Figura 4. Vista del primer patio antes de la intervención

Fuente: Expediente Integral de Restauración y Puesta en Valor de la Casa Concha, por J. Cano Pozo. 2006, Cusco Perú: Instituto Nacional de Cultura.

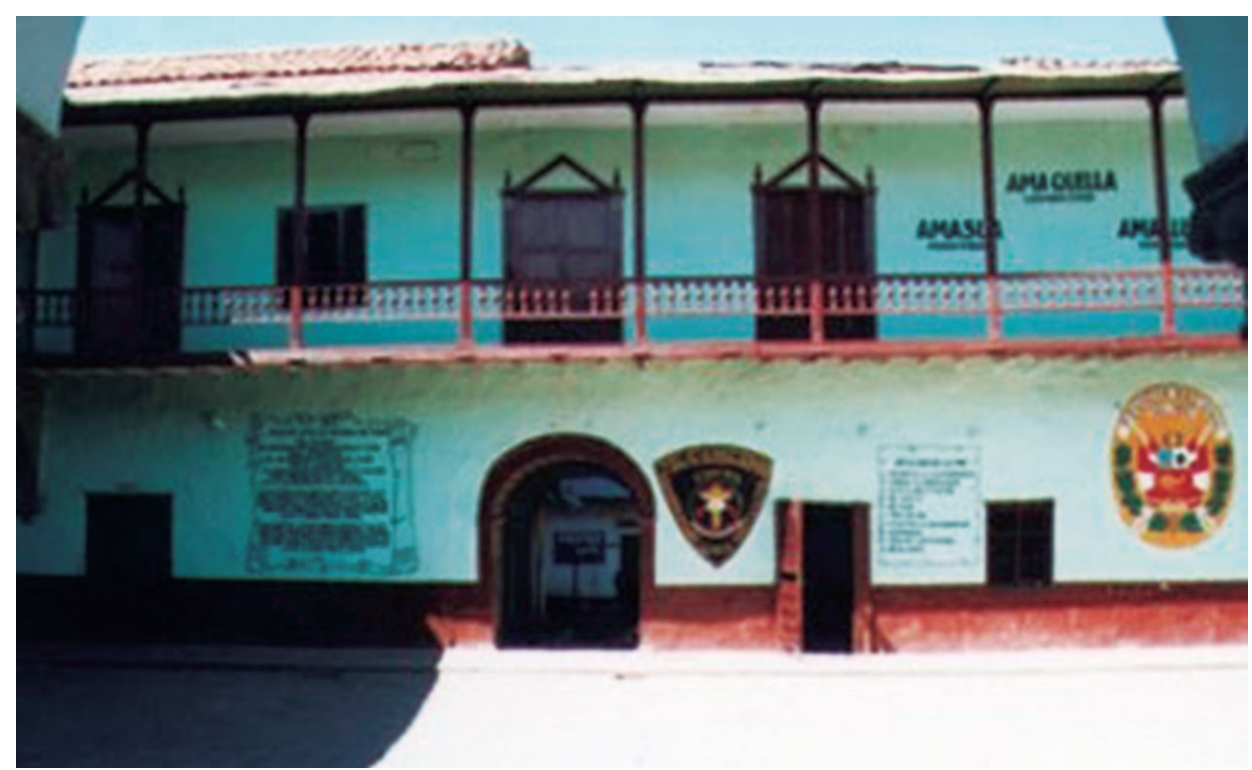

Al segundo patio, que ha sufrido modificaciones sustanciales, se accede a través de un zaguán con arcos de medio punto en piedra, el cual tiene en su inicio una hermosa puerta de madera torneada tipo cancela. El acceso al tercer patio es por un zaguán un poco más estrecho que el del segundo patio, el cual posee un arco de adobe al pie del zaguán y desemboca en un patio rectangular. El cuarto patio es un espacio arquitectónico que cuenta con dos alas de arquerías de piedra labrada de regular altura, una de las cuales en la actualidad se encuentra tapiada. En el segundo nivel se encuentra una galería de madera tallada que da acceso a dos ambientes pequeños. El ala Sur de la Casa Concha presenta una arquería de piedra en el primer nivel. En el ala Este existe un vano abierto que da paso a un quinto patio.

\section{Análisis}

En el proceso de restauración y puesta en valor de la Casa Concha se han conservado las características espaciales y morfológicas originales. Respetando la distribución de la casa, se han conservado los cinco patios, y los materiales utilizados son los mismos de la época: piedra para la cimentación y sobrecimentación, muros de piedra, muros de adobe, estructura de techo de madera y teja de arcilla. Se han respetado las características especiales de la decoración, los balcones, la carpintería de madera y las pinturas murales.

La fachada es un claro ejemplo de la casa virreinal cusqueña edificada sobre una kancha inca. Los muros de piedra en la base resaltan los vestigios de la kancha, los muros de piedra en el primer nivel demuestran la mampostería de transición (entre lo inca y lo virreinal), y los muros de adobe de la segunda planta y los balcones labrados resaltan el aporte virreinal. Se puede leer claramente la superposición de las diferentes etapas de intervención: inca, transición, virreinal y contemporánea.

La Casa Concha en sus orígenes estuvo destinada a vivienda. Tuvo un uso familiar y social, el cual se puede diferenciar claramente por el tipo de distribución. Se distinguen dos sectores: el señorial, que corresponde al primer y segundo patio, donde se hallaban el salón principal, los dormitorios familiares y el de visitas, los depósitos de productos y la despensa familiar, que se comunican a través de corredores y pasadizos; y el de servicio, que se ocupaba el tercer y cuarto patio. 


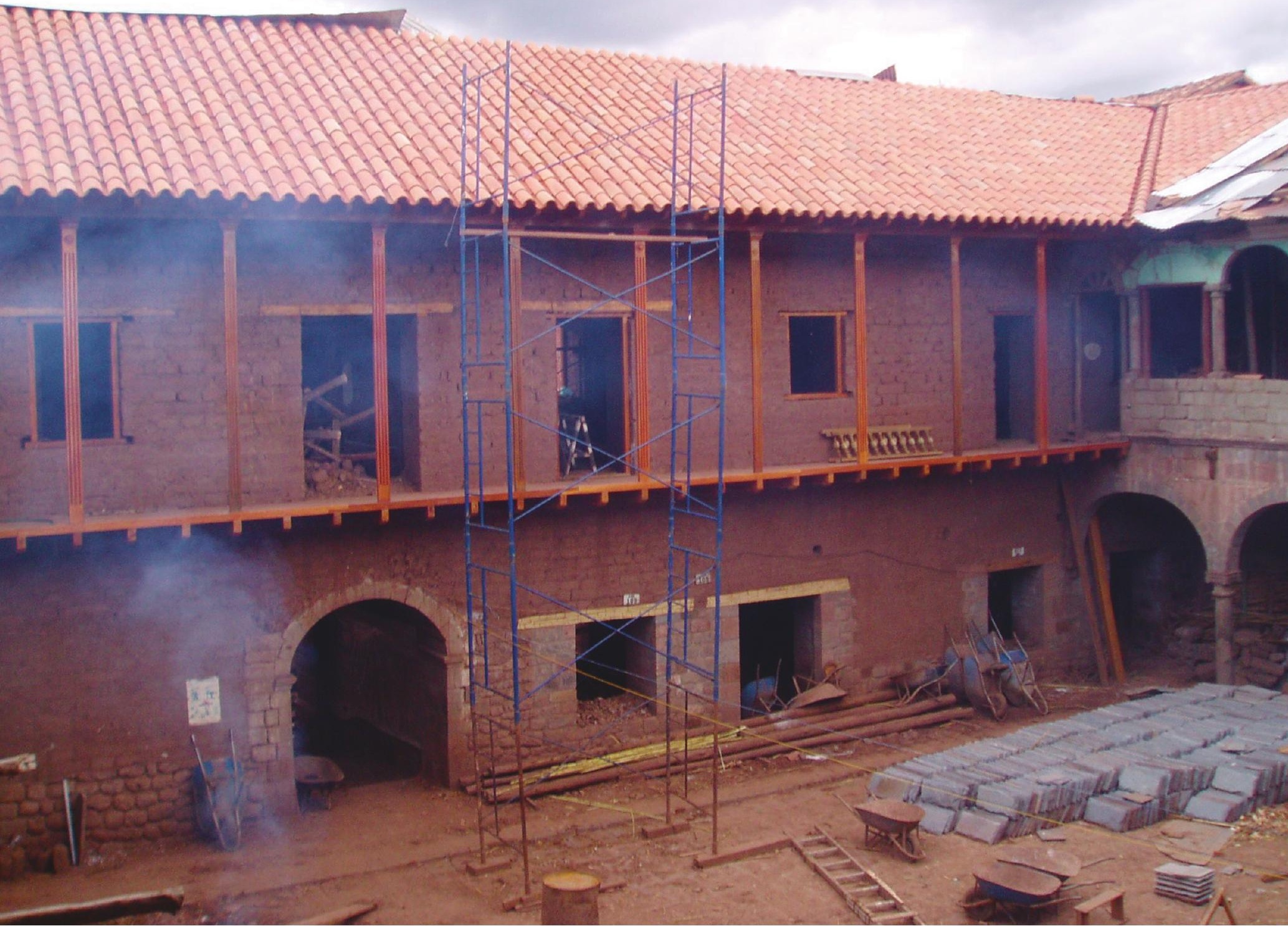

Luego de la puesta en valor, la casa ha sido adecuada para funcionar como un museo, uso idóneo por la amplitud de las habitaciones. El acondicionamiento museográfico fue realizado durante una intervención posterior, ejecutada por un convenio entre la Universidad de Yale y la UNSAAC, diseñada por la Arq. Anne Marshall de Nueva York (Figuras 6 y 7 ).

\section{Mecanismos de gestión}

La Casa Concha fue declarada Patrimonio Nacional mediante la Resolución Suprema Nº 2900-72-ED del 13 de diciembre de 1972. Dentro de la Zona Monumental del Cusco, antes de la intervención fue ocupada por la Policía Nacional del Perú (Unidad Servicios Especiales y Fuero Militar), lapso de tiempo durante el cual se realizaron las modificaciones y deterioros más notables del inmueble, debido a la función que cumplía (disturbios, conflicto social, antimotines) (Aguilar Meza, 2017). Es importante señalar que fue una decisión política a través del Doctor Valentín Paniagua Corazao, presidente transitorio de la República, la que asignó a la Universidad Nacional San Antonio Abad del Cusco el uso de esta casa para fines académicos, mediante Resolución Suprema N 0603-2001-IN del 21 de junio de 2001 (Diario Oficial el Peruano, 2001, p. 204825).

El Ministerio de Comercio Exterior y Turismo encargó al Proyecto Especial Plan COPESCO, amparado en el Convenio Marco de Cooperación, presentó los Términos de Refe-
Figura 5. Vista del primer patio durante la intervención

Fuente: En Informe Final de Preliquidación de la Restauración y Puesta en Valor de la Casa Concha, por J. Cano Pozo 2010, Cusco, Perú: Dirección Desconcentrada de Cultura - Cusco. 
devenir Vol. 4, N7, ENERO- JUNIO 2017, PP. 49-68 - ESTUDIOS | ISSN 2312-7562

UNIVERSIDAD NACIONAL DE INGENIERÍ, LIMA

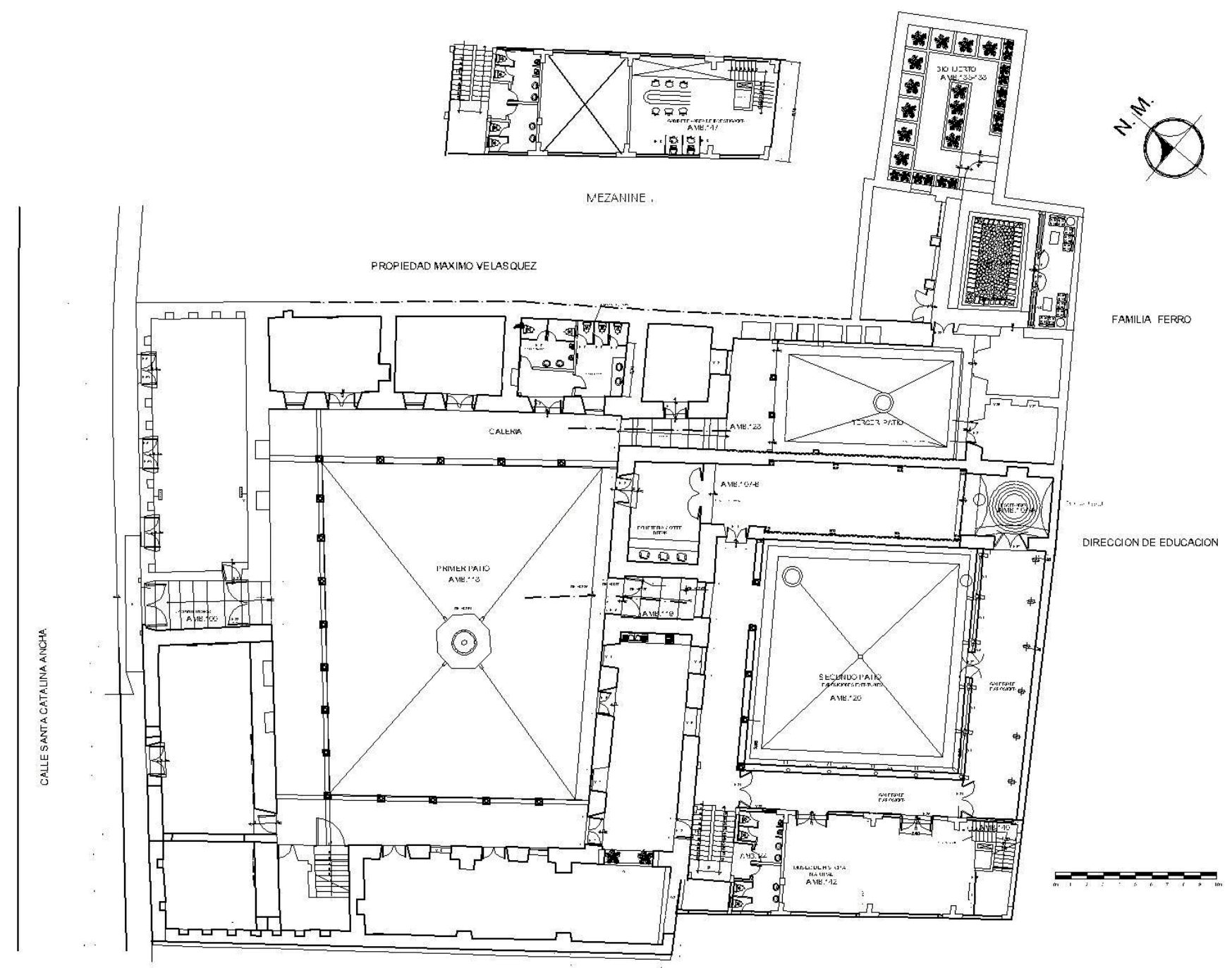

Figura 6. Planta Primer Nivel de la Casa Concha

Fuente: Expediente Integral de Restauración y Puesta en Valor de la Casa Concha, por J. Cano Pozo, 2006, Cusco, Perú: Instituto Nacional de Cultura. rencia para la Restauración y Adecuación a nuevo uso de la Casa Concha, documento que fue evaluado técnica y legalmente, y mereció opiniones favorables. Posteriormente se hizo cargo El Instituto Nacional de Cultura (hoy Ministerio de Cultura-Cusco), en Convenio con la Universidad Nacional de San Antonio Abad del Cusco.

Tomando como base el proyecto se consideró la refuncionalización de los bienes inmuebles patrimoniales. Este concepto, que plantea la defensa del patrimonio construido compuesto por edificios de valor, integrados a conjuntos urbanos pero en estado obsoleto (Gutiérrez, 2001) es relativamente nuevo.

Olga Pizano Mallarino (2010), en su libro La Gestión del Patrimonio Cultural Perspectivas de Actuación desde la Academia, considera algunos criterios preliminares, aspectos para la evaluación de bienes inmuebles patrimoniales refuncionalizados que son pautas calificativas enfocadas a evaluar intervenciones en inmuebles patrimoniales bajo el método de refuncionalización. Ello surge de la necesidad de determinar la incidencia de la nueva función asignada al bien patrimonial, el entorno y la comunidad asociada, se verifica de cinco aspectos: "compatibilidad, transformación, usabilidad, participación y sostenibilidad" (Patiño Zuluaga, 2010, pp. 70-79). 


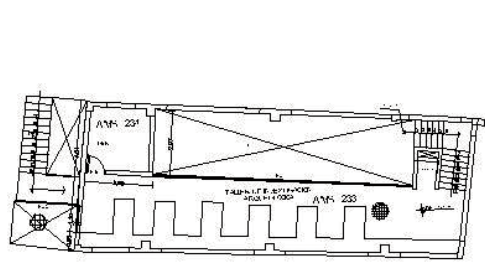

MEZANINE2
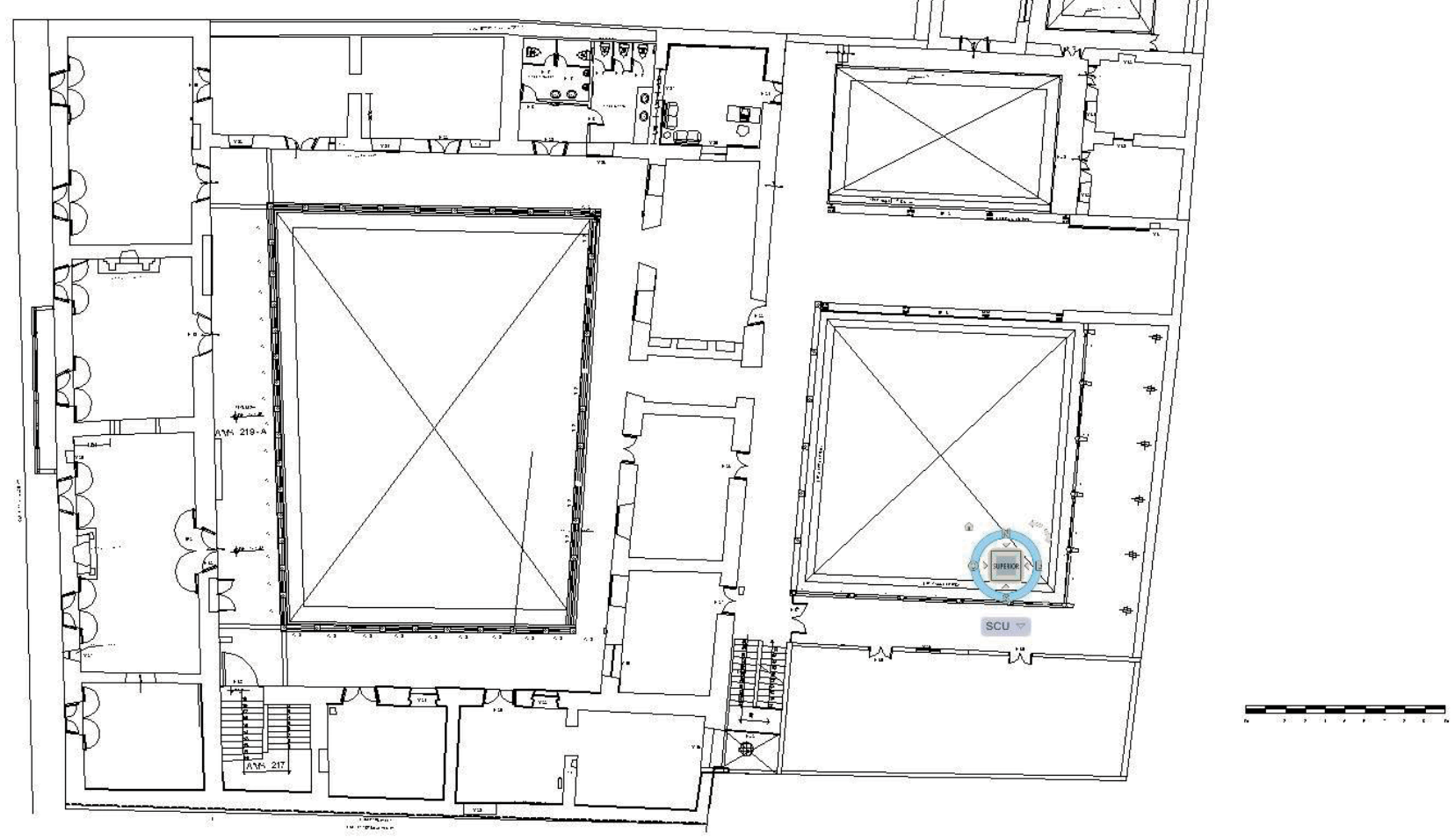

\section{Compatibilidad}

Es la concordancia que existe entre la función actual asignada y la función original, que debe mantener las condiciones esenciales y proteger los valores excepcionales que el inmueble posee. Esta se comprueba evaluando tres aspectos: la teoría propuesta en estudio sobre los usos posibles por subcategorías, la configuración espacial-formal de la edificación y la reglamentación que rige el entorno donde esta se encuentra.
Figura 7. Planta Segundo Nivel de la Casa Concha

Fuente: Expediente Integral de Restauración y Puesta en Valor de la Casa Concha, por J. Cano Pozo, 2006, Cusco, Perú: Instituto Nacional de Cultura. a) Función actual asignada vs. Función subcategoría propuesta Sí cumple (Listado del uso establecido proyecto inicial)

b) Función actual vs. Configuración espacial (Porcentaje de inter- Sí cumple vención)

c) Función actual vs. Reglamentación (Normas que rigen el en- Sí cumple torno inmediato) 


\section{Transformación}

Es la influencia de la nueva función asignada, cualquier modificación importante que experimente el entorno inmediato o circundante, y los efectos consecuentemente positivos en la zona a partir de la intervención. Esta se evalúa a partir de tres aspectos: conservación de la identidad, memoria e imagen del entorno, y densidad y rehabilitación de la zona a partir de la función.

a) Conservación de la identidad, memoria e imagen (Transformó o conservó la imagen de continuidad y permanencia que identifican al entorno)

b) Contraste del entorno respecto al bien (Porcentaje de intervenciones complementarias en relación al bien patrimonial)

c) Rehabilitación de la zona (Verificar si contribuye al mejoramiento de las condiciones urbanísticas)

Sí cumple

Sí cumple

Sí cumple

\section{Usabilidad ${ }^{4}$}

Es la capacidad de un bien refuncionalizado de ser comprendido, aprovechado y a su vez atractivo para el usuario en las condiciones especiales de uso que dependen de la función asignada. Hace énfasis en la relación directa entre los espacios físicos y el usuario; la definición de los atributos internos y externos físicos, que contribuyen a la configuración espacial del edificio que propone el interesado realizar actividades en lugares específicos con resultado de la nueva función; y la aceptabilidad de este frente a estos espacios. Se evalúa a partir de tres categorías:
a) Satisfacción (Medir el grado de aceptación-uso restringido)
No cumple
b) Funcionalidad (Calidad, facilidad, utilidad y comodidad)
Sí cumple
c) Eficiencia (Disposición de los espacios)
Sí cumple

\section{Participación}

Es el poder y la injerencia de los organismos gestores en la decisión y acciones que afectan la refuncionalización. Este reconocimiento debe tomar en cuenta a tres actores:
a) Vinculación de la comunidad asociada (Inclusión de la socie-
Sí cumple dad afectada, vecinos y habitantes del sector; conocer la opinión de los mismos)
b) Condición de los propietarios (Injerencia de grupo)
Sí cumple
c) Contribución de los agentes legales y financieros (Concesión y grupo de especialistas)
Sí cumple

\footnotetext{
4. Término utilizado por el Instituto de biomecánica de Valencia, España, en el Manual de métodos para la selección de ayudas técnicas bajo criterios de usabilidad (2003), pp. 16-20 (Pizano, 2010).
} 


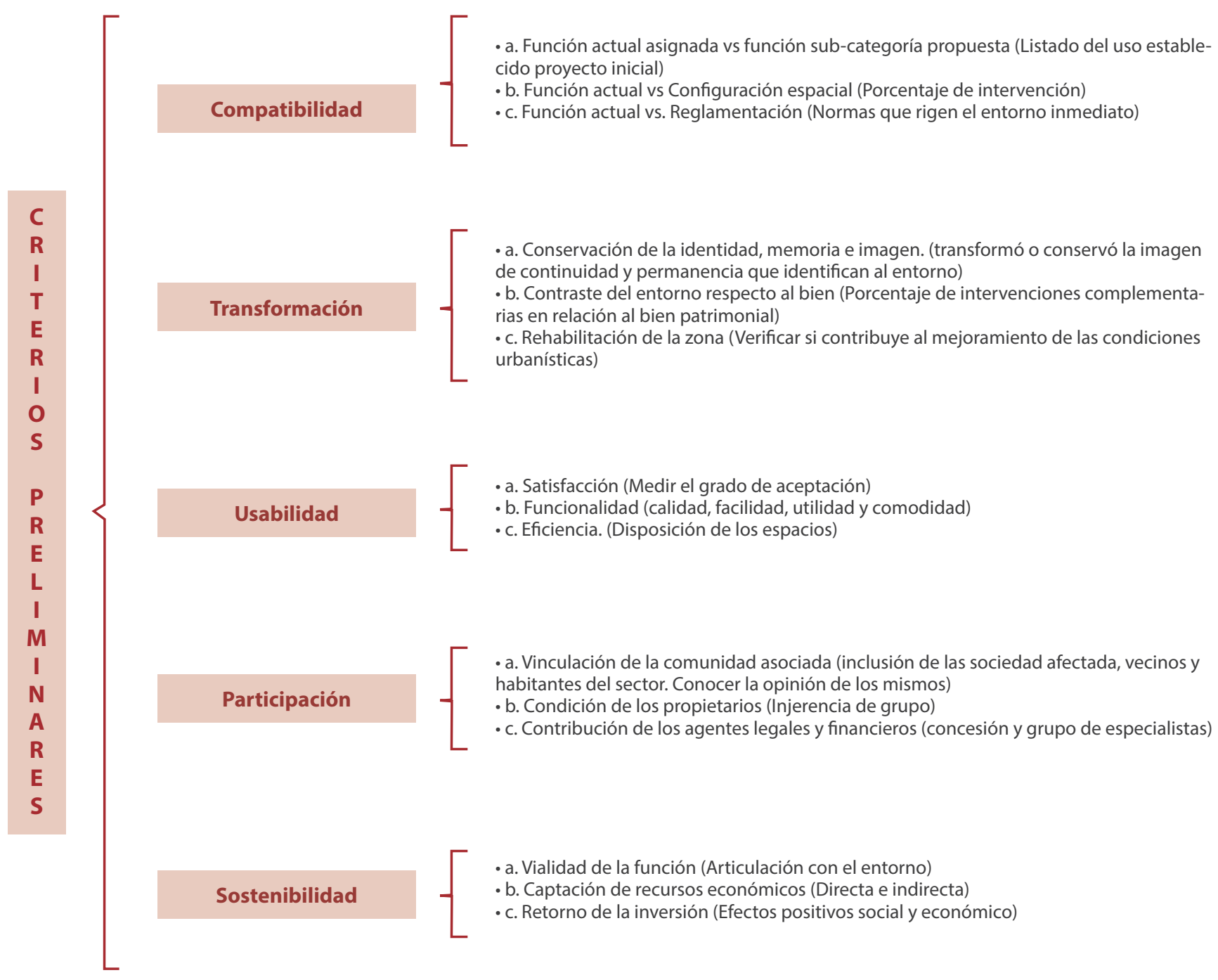

Figura 8. Resumen de la refuncionalización.

Fuente: Elaboración propia a partir del Resumen de la refuncionalización del estudio (p. 90), E. Patiño Zuluaga, 2010.

\section{5.- Sostenibilidad}

Es la capacidad de la función asignada de generar recursos económicos suficientes para mantener la edificación y que esta sea perdurable. La permanencia se logra cuando a partir del uso se genera actividades que permiten al bien abastecerse de recursos sociales, económicos y culturales para su sostenimiento. Se mide evaluando tres aspectos (Figura 8).
a) Vialidad de la función (Articulación con el entorno)
Sí cumple
b) Captación de recursos económicos (Directa e indirecta)
Sí cumple
c) Retorno de la inversión (Efectos positivos social y económico)
Sí cumple 
De acuerdo a la evaluación, la refuncionalización cumple satisfactoriamente con los aspectos mencionados. Sin embargo, en el caso estudiado el tema de participación, que es parte fundamental del proceso y permite asegurar su permanencia en el tiempo, no fue tomado en cuenta, así como tampoco su mímesis con el entorno donde se encuentra, por la apropiación que se ha logrado en parte de la ciudad.

La sostenibilidad propuesta inicialmente era indirecta, debido a su condición de centro cultural y de investigación arqueológica, la cual debió ser subvencionada por terceros. La restauración integral de la casa estuvo a cargo del Instituto Nacional de Cultura Cusco (hoy Ministerio de Cultura) y demandó 4 años (2005-2010). Su finalización coincidió con el acuerdo de cooperación científica entre la UNSAAC y la Universidad de Yale por la colección Bingham de Machu Picchu, de modo que fue una de las opciones que se barajaron para ser sede de su exhibición, depósito y estudio (Falcon Huayta, 2013), función que se ajusta de manera adecuada al entorno y que a su vez genera recursos propios para su sostenimiento.

La utilidad es significativa para las personas que la emplearán, pues generan actividades que puedan sostener sin ayuda de terceros, que sea un potencial de desarrollo para la ciudad y su entorno y lo más importante, que se conserva en el tiempo.

Se recomienda que estos criterios se incluyan en una estructura metodológica que proporcione un instrumento que guíe el proceso de refuncionalización.

El patrimonio cultural construido debe considerarse una oportunidad de desarrollo, por lo que es necesario invitar al sector privado a invertir en la recuperación y mantenimiento de inmuebles patrimoniales, apostando por la asignación de funciones que permitan obtener un provecho en ambas direcciones, conservar el patrimonio y retornar la inversión económica.

\section{Conclusiones}

1. En esta síntesis del contexto histórico y arquitectónico resalta que, a pesar de las ocho décadas transcurridas a partir de la creación del Patronato Departamental de Arqueología del Cusco, la fisonomía del Cusco y su centro histórico ha ido moldeándose de acuerdo al devenir de sucesos económicos, sociales y políticos. El personal técnico-obrero (canteros, alarifes, etc.), en su afán de conservar y restaurar el patrimonio cultural, adecuó sobre las existentes estructuras prehispánicas un nuevo estilo virreinal, de forma que surgieron las casonas cusqueñas; en otros casos muchas de estas casas se subdividieron, se clausuraron y se abrieron calles, de manera que este proceso permitió el surgimiento de una ciudad virreinal, cuyas estructuras y traza han perdurado a lo largo de cinco siglos, conservando y reutilizando la traza inca y parte de sus edificaciones virreinales.

2. La evolución de los procesos de intervención en el patrimonio arquitectónico virreinal en el Cusco se forjó a partir de tres hitos que marcaron la tendencia hasta la actualidad: la creación del Patronato Departamental de Arqueología del Cusco, el sismo que asoló la ciudad del Cusco en 1950 y la creación del Instituto Nacional de Cultura.

3. En cuanto a las intervenciones en el patrimonio edificado virreinal del Cusco, se ha podido verificar la existencia de dos frentes: el primero, a cargo del Estado peruano, quien a través de la hoy Dirección Desconcentrada de Cultura del Cusco (DDC-C) se ha especializado en intervenir el patrimonio edificado de carácter religioso; el segundo, a cargo de inversionistas privados, que han optado por la restauración de la arquitectura civil.

4. Se ha evidenciado existe una constante en las investigaciones preliminares de los procesos restaurativos en edificaciones religiosas realizadas por la DDC-Cusco: una fuerte inclinación a ponderar el análisis formal y estilístico, lo que ha llevado a estan- 
darizar los planteamientos de intervención, y ha devenido en la casi nula necesidad de incorporar un adecuado y sistemático marco teórico-conceptual.

5. Las intervenciones ejecutadas por la DDC-Cusco están complementadas por la participación de un equipo multidisciplinario de especialistas, conformado por arquitectos, arqueólogos, ingenieros y restauradores, quienes tienen a su disposición mano de obra eficiente y altamente calificada en tecnologías constructivas tradicionales.

6. Debido a la limitada capacidad resistente del sistema constructivo del adobe, ante el peligro latente de los sismos, el criterio restaurativo que prevalece en nuestro ámbito es el estructural.

7. El proceso restaurativo ejecutado en la Casa Concha ha respetado el empleo de tecnologías constructivas tradicionales y materiales autóctonos; por tanto, el resultado se considera auténtico.

8. En el proceso de restauración y puesta en valor de la Casa Concha se ha respetado la originalidad y autenticidad de la morfología espacial.

9. LaCasa Concha fue un inmueble deprimido y de conflicto urbano por la presencia de la Guardia Civil o Policía Nacional del Perú (Unidad Servicios Especiales y Fuero Militar), en cuyo lapso de ocupación se realizaron las modificaciones y deterioros más notables del inmueble, hasta que por decisión política se recuperó y revitalizó cumpliendo criterios de refuncionalización (compatibilidad, transformación, usabilidad, participación y sostenibilidad). Actualmente cumple funciones de museo (Cooperación Científica entre la UNSAAC y la Universidad de Yale por la colección Bingham de Machu Picchu).

\section{Referencias}

Cano Pozo, J. (2010). Informe final de preliquidación, restauración y puesta en valor de la Casa Concha. Cusco, Perú: Dirección Desconcentrada de Cultura - Cusco.

Castillo Venero, C. (1970). Cuzco: Patrones de asentamientos (Tesis de bachiller sin publicar). Facultad de Arquitectura de la Universidad Nacional de Ingeniería, Lima.

Conferencia Internacional sobre Conservación. (2000). Carta de Cracovia. Principios para la conservación y restauración del patrimonio construido. Cracovia, Polonia.

Consejo Internacional de Monumento y Sitios. (1999). Carta de Burra, Carta de ICOMOS Australia para Sitios de Significación Cultural.

Consejo Internacional de Monumentos y Sitios. (1964). Carta de Venecia.

El día. La reconstrucción del Cuzco. (14 de noviembre de 1951). El Sol del Cusco, p. 6.

Falcon Huayta, V. (2013). El Museo Machu Picchu de la Casa Concha, Cuzco. Haucaypata, 6-21.

Gutiérrez, R. (2001). Patrimonio para todos, un futuro para la arquitectura industrial. En Instituto Andaluz del Patrimonio Histórico. Preservación de la arquitectura industrial en Iberoamérica y España (pp. 128-135). Granada, España: Comares.

Gutierrez, R., De Azevedo, P. \& Viñuales, G. (1981). La Casa cusqueña. Argentina: Departamento de Historia de la Arquitectura Universidad Nacional de Nordeste.

Instituto Nacional de Cultura. (2007). Documentos fundamentales para el patrimonio cultural. Textos internacionales para su conservación, protección, difusión y repatriación. Lima, Perú: Biblioteca Nacional del Perú.

Kluber, G. (1953). Cuzco, reconstrucción de la ciudad y restauración de sus monumentos. Informe de la Misión enviada por la UNESCO. París, Francia.

Ministerio de Educación Pública. (13 de junio de 1929). Legislación Arqueológica Peruana. Lima.

Normas Legales El Peruano. (21 de junio de 2001). Autorizan al Ministerio para que la PNP haga entrega del inmueble al CTAR Cusco, destinado al funcionamiento de un complejo cultural y de investigación arqueológica, p. 204825. 
devenir Vol. 4, N7, ENERO - JUNIO 2017, PP. 49-68 - EstudIOS | ISSN 2312-7562

UNIVERSIDAD NACIONAL DE INGENIERÍA, LIMA

Patiño Zuluaga, E. (2010). La refuncionallización de bienes inmuebles patrimoniales criterios para asignar función. Bogotá, Colombia: Red de Editores Universitarios de Asociacion de Universidades Confiadas a la Compañía de Jesús en América Latina.

Samanez Argumedo, R. (1991). La casa de don Jerónimo Luis de Cabrera y de la Cerda en el Cusco, su historia y restauración arquitectónica. Revista del Museo e Instituto de Arqueología, 297.

Samanez Argumedo, R. (2016). La Restauración del Patrimonio Monumental de Cusco, antes y después de la Carta de Venecia. Revista del Instituo Americano del Arte, (20), 114.

San Cristóbal, A. (2001). La Casa Virreinal Cusqueña. Lima, Perú: Facultad de Arquitectura Urbanismo y Artes. 